\title{
Transformation of Online Teaching Practices through Implementation of Appreciative Inquiry
}

\author{
Bruce A. Johnson \\ American Public University System
}

\begin{abstract}
The purpose of this case study was to explore the application and outcome of appreciative inquiry as an online instructional strategy for the development of three specific factors: adult learner motivation, engagement, and performance. Appreciative andragogy was an original phrase developed for this study and is an adaptation of appreciative inquiry. Appreciative inquiry has been successfully utilized within organizations to facilitate change and development, while enhancing employee motivation, engagement, and performance. Because there is little research concerning the application of appreciative inquiry to an academic environment, elements of appreciative inquiry were implemented as an instructional strategy within undergraduate and graduate online classrooms. The appreciative inquiry model was adapted for this study as appreciative andragogy and utilized over a four-week implementation period. The participants worked with selected students from their online class and they measured the three factors (motivation, engagement, and performance) before and after the implementation phase. The findings of this study indicate that appreciative andragogy can be applied as an instructional strategy in any online classroom regardless of the subject matter and it holds the potential to have a positive impact on the online learning classroom environment. The study concluded that appreciative andragogy has an ability to take the distance out of distance learning.
\end{abstract}

\section{Introduction}

The online classroom has not impacted the basic principles of adult learning. Rather the format of adult learning has been impacted by the enabled use of technology. The process of adult learning in any classroom environment involves the acquisition of information, interaction with that information through activities, and the creation of new knowledge. The classroom provides a learning environment that becomes the context for knowledge acquisition by establishing conditions that are conducive to learning. The structure of this environment determines the overall effectiveness of the learning process (Caffarella, 2002).

Within a traditional classroom the instructor is physically present and it is that presence that maintains social interactions and builds relationships with the students. The instructor can gauge the level of student motivation and adapt the instructional methods used based upon what is physically observed. Also visible to the instructor is the student's level of engagement and participation in the class. In addition, the instructor is available to observe, guide, and discuss the student's performance and address any potential issues. These physical observations are often absent from the online classroom environment.

The online classroom may change the nature of students' motivation, engagement, and performance. A student's need for self-motivation and taking responsibility for his or her class 
participation and assignment completion may be greater with an online classroom. Some students use assignment deadlines and grades as their source of motivation. The online student's engagement in the class is usually encouraged through the use of discussion boards and asynchronous interactions with his or her instructor. Performance in an online classroom environment is based upon the student's work product, whether this is accomplished through group activities, online assessments, or written assignments. Students are provided feedback from their instructor and the level of feedback can vary from a letter grade to the number of points earned, or the inclusion of developmental comments. Depending upon the level of involvement by the instructor and the student, the online classroom has the potential to become very mechanical in nature and it may become easy for a student to experience a sense of disconnection from the class and/or the instructor.

Another environment where issues of individual motivation, engagement and performance are studied can be found within the organizational setting. These issues are considered essential factors of a successful employee and lead to improved overall organizational performance. The field of organizational development has produced numerous theories of employee development-one theory that addresses development from a positive frame of reference is appreciative inquiry. David Cooperrider and Suresh Srivastva developed appreciative inquiry in 1987 as a means of facilitating organizational change through the use of a positive approach (Orem, Binkert, \& Clancy, 2007). Appreciative inquiry has been successfully utilized within organizations and has demonstrated an ability to affect individual motivation, engagement, and performance. Due to this success of appreciative inquiry and its ability to impact individuals as well as organizations, it has the potential to be adapted to other environments, including the online classroom environment. As an instructional method, appreciative inquiry has a potential to help bridge the gap between the instructor and student within an online classroom. Appreciative inquiry also has the potential to assist in the development of positive working relationships, which in turn may improve the student's motivation, engagement, and performance.

\section{Background of the Study}

Within an online classroom environment, instructors and students will typically interact through class discussion boards and other activities that require instructor and student involvement. The primary methods of meaningful interaction occur through the submission of assignments by the student and the feedback that is provided by the instructor. Assignments are the most common forms of student work products in online classrooms. The feedback an instructor provides may include the points or grade earned, without any further explanation. Feedback may also include the use of rubrics and comments that address the content and mechanics of the assignment. There are also varying levels of comments used, from a "met requirement" or "did not meet the requirement" to detailed narratives that address developmental issues and concerns.

With feedback there may be a tendency to focus on compliance, from due dates to meeting the assignment criteria. The feedback provided may also highlight deficits in the assignment or the student's abilities. If a student believes his or her feedback is nothing more than a canned response or if a grade was provided without any explanation that supports his or her development, the student may not feel encouraged to continue putting forth his or her best effort and it is possible they can experience a feeling of disappointment. An instructor's feedback has the potential to build relationships and influence engagement, motivation, and performance; however, feedback that is focused on negative aspects can discourage a student, especially given that the instructor is not physically present to address his or her issues and concerns.

Within organizational environments appreciative inquiry has been used to affect organizational change by examining what has worked well and looking for the sources of excellence (Watkins \& Mohr, 2001). To accomplish this goal, employees are asked to consider peak times, and an emphasis is placed on positive attributes that contribute to peak performance (Van der Haar \& Hosking, 2004). Appreciative inquiry takes a positive approach to change (Cooperrider, Whitney \& Stavros, 2008) and the development of relationships rather than placing an emphasis on employee and organizational deficits. An appreciative 
method of development is asking employees to consider his or her strengths and how to build upon those attributes, which changes the mindset of the employee. Instead of trying to force changes in his or her performance, a positive method of development results in a sustained level of improved performance (Van Oosten, 2006). This approach encourages employee motivation, increases employee engagement in his or her job, and results in an employee performing at a higher level than the employee who is continuously reminded of what they are doing wrong and what has not work well in the past.

There has been little research exploring the application of appreciative inquiry to an academic environment. One adaptation of appreciative inquiry has been called appreciative pedagogy and its primary purpose was to address assignments used in a traditional classroom (Yballe \& O'Connor, 2000). Appreciative inquiry has the potential to be adapted as an instructional strategy that could bridge the gap between an instructor and his or her students. The goal of this adaptation of appreciative inquiry is to increase student motivation, engagement in the classroom, and improve his or her performance. Appreciative inquiry has already been noted for its usefulness in any relationship that is social in nature (Van der Haar \& Hosking, 2004), which supports its use in a classroom environment. Further support of the use of appreciative inquiry is the potential that a positive classroom experience holds for influencing increased student motivation (Darabi, Nelson, \& Paas, 2007). This adaptation of appreciative inquiry has been labeled appreciative andragogy.

Andragogy is a theory that addresses how adults learn and is distinguished from the theory of pedagogy or the instruction of children. The basic premise of andragogy holds that adult learning occurs through a process of action and self-reflection (Cooper \& Henschke, 2006). Appreciative andragogy emphasizes the positive nature of adult learning and the enhanced view of self that will occur through supportive interactions with an instructor. Through the use of appreciative andragogy as an instructional method, the instructor may have a tool that can build nurturing relationships and increase the instructor's presence within an online classroom environment. With a positive approach to student development the student is likely to experience a greater sense of motivation, engagement in the classroom, and improved performance overall.

\section{Statement of the Problem}

It is not known if an appreciative inquiry approach has a positive effect in an online postsecondary classroom environment. Appreciative inquiry is an organizational development tool that has been used to affect change and influence employee performance. Elements of appreciative inquiry have not been applied directly to an online classroom environment as a means of influencing the online student's performance, engagement, and motivation. Appreciative andragogy is an adaptation of appreciative inquiry, developed as an instructional method to influence the adults' level of motivation, engagement in the classroom, and overall classroom performance.

\section{Purpose of the Study}

The purpose of this multiple case study was to explore the application and outcome of appreciative andragogy as an online instructional strategy for the development of adult learner motivation, engagement, and performance from multiple perspectives. Each individual case consisted of one instructor applying appreciative andragogy to his or her classroom. A final cross-case analysis is presented, which highlights common themes found among all of the individual cases. The participants of this study were instructors facilitating online courses for an online university. The participants were solicited through a formal announcement issued through a university's faculty website and through a professional networking website with members that are online instructors. The participants were not confined to one demographic region as the online courses taught by the participants were not limited to one demographic region. 


\section{Research Questions}

\section{Central research question:}

How does the application of elements of appreciative andragogy as an instructional strategy for instructors positively affect online post-secondary classes?

\section{Subordinate research questions:}

1. How do online instructors apply elements of appreciative andragogy as a positive instructional strategy for online post-secondary classes?

2. How does the application of elements of appreciative andragogy as an instructional strategy for online instructors influence adult learner motivation?

3. How does the application of elements of appreciative andragogy as an instructional strategy for online instructors influence adult learner engagement?

4. How does the application of elements of appreciative andragogy as an instructional strategy for online instructors influence adult learner performance?

\section{Theoretical / Conceptual Framework}

Appreciative inquiry was developed as an organizational developmental process and change initiative method. The act of appreciation includes acknowledging each employee's value and abilities, and inquiry is an exploratory process that uses questions as a form of communication (Whitney \& Trosten-Bloom, 2003). Appreciative inquiry is based upon social constructivism, which is the individually held and socially constructed image of reality that each employee creates (Walker \& CarrStewart, 2004). An employee will act according to their beliefs about this subjective view of reality (Watkins \& Mohr, 2001) and the perception of reality can only change when the underlying beliefs used to create that reality are understood (Orem, Binkert, \& Clancy, 2007). Appreciative inquiry creates a positive frame of reference by allowing employees to collaborate and contribute towards the development of a shared vision (Van der Haar \& Hosking, 2004). Organizational development and change processes can only occur when an employee shares the organization's future vision as part of their own reality (Cooperrider, Whitey, \& Stavros, 2008).

Appreciative inquiry is also based upon the positive principle, which holds that any type of change process that results in an employee working at their maximum capacity can only occur when it is developed from a positive perspective (Whitney \& Trosten-Bloom, 2003). An employee who feels valued, who can contribute to the organization's future, and is allowed to make choices about their involvement in the work environment are also more likely to be engaged, productive, and actively involved in the organization, which also results in strong working relationships (Bushe \& Kassam, 2005).

\section{Literature Review}

\section{Andragogy}

Andragogy is a model of learning that makes a distinction between teaching adults and teaching children (Sheridan, 2007). The term andragogy is most often associated with Malcolm Knowles, as Knowles developed andragogy as a means of describing the characteristics of an adult learner (Merriam, 2001; Rachal, 2002; Sheridan, 2007). The premise of andragogy is that the adult has a need to learn and a willingness to take responsibility for that learning, the adult possesses life experiences that must be acknowledged, and an adult has both the readiness and motivation necessary to learn (Knowles, Holton III, \& Swanson, 1998). Facilitating adult learning can be customized for maximum effectiveness by clarifying the important characteristics of an adult learner and the needs that are specific to adults.

Andragogy takes into consideration the characteristics of an adult and explores how those characteristics influence adult learning; whereas, pedagogy is a term used to describe the nature of teaching children. An adult has life experiences that may influence the learning experience, while a child 
The Transformation of Online Teaching

is often in the process of learning how to learn. The adult learner may possess motivation to learn because of needs, goals, or specific problems, whereas a child often participates in the learning process because it is a mandatory requirement. The strongest source of motivation for an adult learner is his or her internal sense of self-worth, self-esteem and self-identity, which is not fully developed in a child (Ozuah, 2005; Rachal, 2002). In addition, the adult is likely to take responsibility for his or her learning and become actively involved in the learning process. A child is learning to become responsible and the knowledge provided is often factual in nature. The distinctions between an adult and a child helps to inform the process of facilitating adult learning and has led to the development of methods that are designed to facilitate learning rather than teach the process of learning.

Another relevant distinction between adults and children is the self-directed nature of learning by the adult learner. Children tend to be passive participants in the learning process as they are recipients of instructor knowledge. An adult tends to be an active participant in the learning process because they have chosen the formal classroom for specific purposes and needs, and the adult is often willing to take a responsible role in the learning process (Bolton, 2006). An adult learner may not expect to be given knowledge by his or her instructor (Raelin, 2007). However, an instructor is often expected to provide optimal learning conditions. The adult also has specific societal roles that can further shape his or her needs, including career development, job responsibilities, family responsibilities, and social status (Forrest \& Peterson, 2006).

Adults have an ability to learn informally from their daily interactions and experiences, or they may seek out knowledge on their own (Merriam, 2001). When adults enter a formal classroom they are often seeking to participate in the process of learning for a specific purpose, as a means of gaining specific, relevant, and meaningful knowledge (Patterson \& Crooks, 2002). Due to the need to learn and acquire individualized knowledge, the pedagogical role of teaching children who may be dependent upon their teachers to give them knowledge is transformed to an andragogical approach of teaching adults who are often independent learners.

There are challenges that arise when utilizing andragogy as a framework for understanding the adult learner. The primary issue is the transition from childhood to adulthood and the preparedness of a new adult in becoming a responsible, self-directed learner. Individuals who have made a recent transition from childhood to adulthood, because of the change in their age or societal role, may still lack the educational experience necessary to function as independent, self-directed adult learners (Miflin, 2004). The challenge of facilitating the process of learning for new adults can be met when adult learners are understood from an individual perspective, which can be accomplished through constructive dialogue with their instructor. Another challenge for the andragogical approach is that this method may not apply to all learning environments. A pedagogical method may still be necessary in a learning environment where a specific skill needs to be learned and adult learners must be given the required technical knowledge or procedural facts (Ozuah, 2005).

\section{Learner Performance}

Within an online classroom the principles of adult learning do not change; therefore, the nature of a learner's classroom performance would not change, only the environment that the learner is working within. Adults attending a traditional classroom are physically present to take exams, submit written assignments, and demonstrate their learning through other means, including classroom presentations. Learners have an understanding that when they attend a class they will be expected to do some type of work to demonstrate their learning. For an online classroom, the most common form of learning product is the written assignment. An instructor should have an understanding of the potential factors that enhance learner performance and detract learners from optimal performance in an online classroom, as they are not physically present to guide the learning process.

One method of improving learner performance is to have periodic contact with the instructor (Zepke \& Leach, 2006), especially when the instructor is viewed as a source of information and support for the learner (Lyons, Kysilka, \& Pawlas, 1999). Some schools have met this need for contact by having 
instructors hold weekly office hours, requiring instructors to be available at specified times through instant messaging tools, assigning mandatory participation requirements for the discussion board, or by having instructors respond to all learner communication and emails within a specified time period. The need for contact and effective communication in an online classroom environment is often greater than a traditional classroom, as the contact becomes a means of replacing the instructor's physical presence, supplementing the instructor's virtual presence, and supporting the learner's development.

One factor that influences performance is the learner's competence with technology. While learners may be familiar with technology in general they may not be technologically competent to function in an online learning platform (Osika \& Sharp, 2002). Learners' ease with technology influences how well they perform, especially if there is limited prior experience. Another factor influencing performance is the ability of the learning environment to provide a climate that is conducive to cognitive development (Kiely, Sandmann, \& Truluck, 2004). An adult learner who has prior experiences and knowledge needs to be encouraged to do more than memorize facts, as learning is more likely to occur when high-order cognitive processes are utilized. Discussions in an online classroom provide the means necessary for cognitive and intellectual development as all learners and the classroom instructor are expected to participate and contribute. This is in contrast to the traditional classroom environment where discussions usually involve one learner answering a question and receiving a reply from the instructor (Klecker, 2007). Online classroom discussions provide an opportunity for learners to interact with each other and share their experiences, which in turn can deepen the learning and knowledge creation process.

Adult performance in the classroom is often affected by their responsibilities (Lyons, Kysilka, \& Pawlas, 1999). Performance encompasses the quality of the written assignments submitted, the level of involvement in the course, and an ability to demonstrate that progress has been made towards meeting the learning goals and objectives. Performance also includes the level of participation in the classroom discussions, along with the quality of the interactions with other learners and the instructor (Palloff \& Pratt, 2003). It is possible that performance may be adversely affected when adults have taken on too many roles and responsibilities. Performance may also decline if adults have too many demands made of their time or they are not effectively managing their time and balancing coursework assignments with these responsibilities. Within a virtual classroom, where a physical presence is not maintained, adults can easily become disconnected from the class and the learning process, resulting in poor overall performance.

\section{Learner Engagement}

The level of learner engagement in the classroom and the learning process is an important consideration for the online instructor as it is considered to be an action-based state that concerns what the learner is doing. Engagement involves the amount of time, effort, and energy that a learner will put into all aspects of the class (Robinson \& Hullinger, 2008). Engagement involves more than a learner just getting by in his or her class or doing the minimum required to pass the course; engagement is a matter of the learner devoting the time necessary to actively participate in the course and the learning process (Shieh, Gummer, \& Niess, 2008). The issue of engagement has been actively studied in workplace settings as an employee development principle and the same research applies to adult learners, as engagement has been directly related to performance and personal satisfaction (Wefald \& Downey, 2009). When adults experience full engagement in what they are doing they are devoting their full attention to the task and they are enthusiastically involved, highly interested, and experiencing positive emotions (Goleman, 2006).

Factors that influence learner engagement include the connection that is felt or perceived with the class and the emotions that are experienced during the learning process. Adults that are introverts by nature find that they can easily adapt to the online classroom; whereas, adults that are extroverts rely upon a strong, personal connection and find it challenging at times to be fully engaged in the class (Offir, Bezalel, \& Barth, 2007). Emotions also have the ability to increase or decrease learner motivation. The adult learner may experience a range of emotions throughout the course that can adversely impact 
The Transformation of Online Teaching

engagement, including frustration and isolation (Zembylas, 2008). Learners may also find that during times of critical reflection they will experience a range of emotions when exploring their present knowledge, information, ideas and belief systems (Dirkx, 2006). The process of critical reflection can happen while the learner is working on his or her own or during classroom discussions, especially if the words, meaning, or tone of another learner's message is misinterpreted. When learners feel positive emotions and have experiences that produce positive emotions they are likely to be fully engaged in the learning process and actively present in the class.

\section{Learner Motivation}

The five basic principles of motivation include attention, relevance, confidence, satisfaction, and self-regulation (Keller, 2008). An adult's motivation is primarily a psychological state of mind and the source of that motivation can be externally or internally based. External motivation is often the result of grades that the learner hopes or expects to receive, the rewards that are anticipated from completing assignments or the degree program, or the motivation may be the result of societal pressures concerning the adult's career, housing, family, or other lifestyle expectations. Internal motivation can be the result of the adult's needs being met and these needs may include the need for self-esteem, knowledge acquisition, and goal completion. The need for self-esteem is a greater factor among younger adults than it is with older adult learners (Kelly, 2007). The need for specific knowledge is related to an adult's decision to pursue an educational program, whether to advance his or her career or meet other societal expectations. Adults are likely to complete the educational goals that they have begun because of these external or internalized needs, which helps to maintain their motivation throughout the duration of his or her course.

The adult's internal motivation is also influenced by a sense of identity established throughout the learning process (Wlodkowski, 1999). An identity can be formulated or shaped by interactions with other learners or through the perceptions and expectations held by the adult learner. A positive classroom experience can lead to a positive self-image. As self-directed learners, adults are also expected to take responsibility for their self-motivation, whether the source of that motivation is external or internal. Adults will hold motivational beliefs about their ability to learn and the relevance of the information received throughout the learning process (Artino Jr., 2008). An adult learner is more likely to stay motivated when they believe the task they are asked to do can be completed, there are resources available to assist them, and the information acquired will lead to the creation of knowledge that is relevant to their needs and lives.

Motivation has been directly linked to a student's overall success in the learning process (Menchaca \& Bekele, 2008; Rovai, Ponton, Wighting, \& Baker, 2007). What is most effective for sustaining continued motivation are conditions within the classroom environment that allow the adult learner to experience positive emotions and a feeling of being connected to the class (Notar, Wilson, \& Montgomery, 2005). A strong working relationship with the instructor, one that provides support and guidance for the learner's progress and development, helps to create a positive emotional state and sustain the learner's motivation. An adult may or may not have a built-in support system from family members or friends and this can influence motivation as the learner experiences challenges with the course or assignments. Other factors that have an impact on learner motivation include self-discipline, selfconfidence, and technological issues. The level of motivation will decrease if there is a lack of selfdiscipline (Li \& Irby, 2008) or self-confidence in the adult's ability to be involved in the learning process (Ahl, 2006). An adult can also be discouraged if they experience challenges with the technology required to participate in the online learning platform (Motteram \& Forrester, 2005).

\section{Appreciative Inquiry}

The concept of appreciative inquiry originated with David Cooperrider and Dr. Suresh Srivastva in 1985 through a dissertation study conducted within the Weatherhead School of Management, Case Western Reserve University (Cooperrider, Whitney, \& Stavros, 2008; Watkins \& Mohr, 2001; Whitney \& Trosten-Bloom, 2003). As appreciative inquiry was further developed, its underpinnings were based upon 
the theory of social constructivism, which provides a correlation between images that are held individually and the perception of reality created from those images (Watkins \& Mohr, 2001; Van der Haar \& Hosking, 2004). Individuals hold a view or perception of the world they live in and these are powerful images that have been individually constructed. This perception of reality is a socially constructed process and developed as a result of the interactions and relationships that an individual has with others (Walker \& Carr-Stewart, 2004). It is believed that a perception of reality can change only when an individual understands the nature of what they believe and the language they have used to create that reality (Orem, Binkert, \& Clancy, 2007).

In addition to a theoretical base, appreciative inquiry is further defined by five principles, including a constructionist principle, simultaneity principle, poetic principle, anticipatory principle, and a positive principle (Cooperrider, Whitney, \& Stavros, 2008; Watkins \& Mohr, 2001; Van Oosten, 2006). The constructivist principle maintains that conversations create meaning, communication influences our perception of reality, and knowledge is also a reality that is subjectively held on an individual basis (Whitney \& Trosten-Bloom, 2003). In addition, the beliefs that are held about reality further determine the way a person acts and behaves (Watkins \& Mohr, 2001). The principle of simultaneity relates change to inquiry; that questions as a form of inquiry set the stage for change (Cooperrider, Whitney, \& Stavros, 2008). Questions also lead to the development of innovative, new ideas (Whitney \& Trosten-Bloom, 2003) and a process of renewed discovery (Watkins \& Mohr, 2001).

Appreciative inquiry is based upon the act of appreciation and the premise of inquiry. Both of these concepts are important tools for change initiatives; however, when combined they bring about a very specific form of guided improvement. From a developmental viewpoint, appreciation refers to acknowledging the value that a person holds and inquiry denotes a process of exploration as a means of enhancing the learning process (Whitney \& Trosten-Bloom, 2003). When an employee experiences appreciation they feel a sense of being valued and the most effective method of inquiry, when used as a means of understanding relevant issues, occurs through the use of questions (Watkins \& Mohr, 2001). Appreciative inquiry involves more than showing appreciation and asking questions, there is a combined purpose of uniting the two processes as a means of creating a shared vision or images about the future (Cooperrider, Whitney, \& Stavros, 2008). When employees begin to share a common purpose their relationships are strengthened (Bushe \& Kassam, 2005).

\section{Application of Appreciative Inquiry to Adult Education}

A technologically-enabled online classroom brings together adults and instructors for the purpose of learning, meeting specified learning goals and objectives, and creating knowledge. The classroom environment is created through the processes and interactions that occur between the learners, instructors, and information provided. The adult learner is self-directed, according to the principle of andragogy, which means that his or her ability to learn depends on his or her involvement in the process and the ability of the learning activities to meet his or her needs. The online instructor facilitates the learning process, while acting as a guide, coach and mentor for the adult learners. The instructor interacts with learners, builds working relationships, communicates with learners, and uses instructional strategies that include written feedback. The adult learners have performance expectations that include demonstrating their progress throughout the process of learning, as well as an expectation that they will be motivated and engaged in the class.

The adult learning process is an active, developmental effort that involves numerous interactions. The adult learner is interacting with his or her instructor, the information presented or acquired, and the classroom environment. Through an adult's performance, engagement, motivation, and interactions in the online classroom meaningful knowledge may be constructed. The learning process is similar to the organizational developmental process as the focus is placed on employee performance, engagement, motivation, and the interactions of employees within the organizational environment. Appreciative inquiry has been utilized to improve employee performance, engagement, and motivation through the use of positive interactions. 
The adult learning process could also benefit from the use of appreciative inquiry by enhancing the learner's performance, engagement, and motivation, through positive interactions with his or her instructor and the classroom environment. A positive approach towards learning is also likely to enhance the knowledge creation process. There have been few applications of appreciative inquiry to a learning environment described in the literature and none that were found applicable to an online classroom. Appreciative inquiry was applied to a traditional classroom as a test process called appreciative pedagogy, specifically "in both undergraduate and MBA organizational behavior classes" (Yballe \& O'Connor, 2000, p. 478). The adult learning process and all learning activities were greatly enhanced through the use of a positive state of mind during the implementation of appreciative pedagogy.

When adults are included in the process of learning and knowledge creation they are also encouraged to use high-order cognitive functions, including critical thinking and critical reflection. An adult begins to examine the meaning of his or her experiences through critical thinking (Dabbagh, 2004) and the use of reflection is an active part of the appreciative inquiry process. The process of learning also involves the adult's emotions (Merriam, 2008) and a positive classroom experience can impact his or her performance, motivation, and engagement in his or her work. For the purpose of this study the phrase appreciative andragogy was utilized as a means of examining how appreciative inquiry elements can be applied to the online classroom environment for the purpose of having a positive impact on the adult's level of performance, engagement and motivation.

\section{Methods}

For this research design a choice was made between utilizing a quantitative method and a qualitative method of data collection, based upon the research purpose and research questions. This study was conducted as a means of exploring enhanced instructional strategies that can help overcome barriers to adult learning (specifically performance, motivation, and engagement issues) within an online classroom environment. Appreciative inquiry has been chosen because of its ability to have a positive impact on adult performance, motivation, and engagement in an organizational environment. There are limited research studies available that address the use of appreciative inquiry within an online academic learning environment. Appreciative inquiry has been effective with enhancing working relationships within organizations and due to its positive nature there is a possibility that it can also enhance instructor and learner relationships.

A qualitative research design was chosen for this study as this type of research is best suited for research subjects that have limited existing research or theories (Creswell, 2003). There are numerous theories concerning adult learning; however, there are few theories and limited research that address the use of appreciative inquiry as an instructional strategy in an online classroom environment. This study provided a description of participants' experiences as they attempted to work with the concept of appreciative andragogy and utilize appreciative andragogy in their online classrooms. A quantitative study will make predictions from numerical data and a qualitative study will examine variables within a natural environment (Sogunro, 2002). This feature of qualitative research further supports the decision to utilize a qualitative research design for this study. For this study it is also important that the concept of appreciative andragogy be tested in an existing online course; therefore, a qualitative study matched the necessary context of this study. In addition, the participants' online facilitation expertise was more important for this study than the subject matter of the course, as the research questions presented were applicable to any online course. The study was bound by a set period of time during a participants' current online class.

\section{The Research Site}

This study explored strengthening the instructional practices of an online instructor through the application of appreciative andragogy. The researcher was not interested in studying the methods or practices of a particular online school or university, including any grading forms, guides, or any other 
materials that the school may provide the instructor. The participants were given a concept to work with and asked to apply it to their online classrooms. Each participant has a unique or individualized way of relating to his or her students, which is a unique characteristic of the participant rather than a methodology provided by the school. Appreciative andragogy was viewed as a tool that would be made available to the instructor as a means of enhancing his or her facilitation practice, with the impact of student development studied. The subject matter taught by the participant is not relevant to the study as these strategies would be applicable to any online course. Because this is a multiple case approach, there were multiple research sites.

One of the proposed research study sites was an online university situated in the United States and is accredited by The Higher Learning Commission (HLC). This online university was also chosen because the potential online instructor population could provide more than enough participants for this case study. The participating university indicated the provisional access would be granted provided all conditions established by their Office of Institutional Effectiveness were appropriately met. These conditions included a completed proposal and IRB application form, along with other stipulations established by their legal department. The process of requesting permission was completed and all conditions were met. It was mutually agreed any published form of this dissertation would not reveal the identity of this university or the participants.

\section{Participants}

For a qualitative study, a small number of participants are selected as a purposeful sample rather than serving as a representation of the entire population, which is used in quantitative studies (Sogunro, 2002). Following the guidelines for a successful multiple-case study, there were a total of nine cases, involving nine participants. Each case utilized one instructor as the unit of analysis. The voluntary participants of this study consisted of instructors facilitating online courses. The average age range for the participants was 40 to 60 years old. Other demographic characteristics had no bearing on this research study and therefore were not taken into consideration. An online instructor teaching at the undergraduate level is required to have a master's degree at a minimum, while an instructor teaching at the graduate level is required to hold a terminal degree. For the primary online university utilized in this study, the participants were solicited through a formal announcement issued through the university's faculty website. These participants facilitated online classes at the undergraduate level. Additional participants for this study were obtained through an announcement posted on the professional networking website, LinkedIn. The participants obtained from this source had varying levels of education and experience, along with a background of facilitating online courses at the undergraduate and graduate level for multiple universities.

The primary concern for selecting participants was their background, including experience facilitating online classes. Online instructors may be hired by an online university as full-time faculty members or adjunct faculty members based upon their facilitation experience, work-related experience, or a combination of the two skill sets. The level of experience, in terms of the actual number of years that the participants' have facilitated online courses, did not influence the study results as the researcher was interested in learning about the instructor and learner interactions, along with the instructional strategies utilized to influence performance, motivation, and engagement in the online classroom when appreciative andragogy was introduced. Once the initial interviews were conducted the researcher evaluated each potential participant with a goal of selecting six to ten participants. The final determination of participants for the study was made based upon participants' willingness to participate voluntarily in the study, their prior experience facilitating an online course, their willingness to commit the time necessary to participate in the full range of activities designed for the study, and the ability of the researcher to obtain permission from their online university to use the participants' online classrooms as research sites. Those applicants who were selected as participants were then contacted and all necessary permission and consent forms were provided. 


\section{Application of Appreciative Andragogy}

Appreciative andragogy was applied as an instructional strategy by utilizing the 4D cycle that was developed for appreciative inquiry. The goal of an appreciative andragogy 4D cycle is to enhance the development of the instructor's relationship with their students over a four-week period. The first week consisted of contacting each of the selected students and having a conversation with them, utilizing the Discovery and Dream processes. Discovery is a process of learning about each student's hopes, dreams, and prior peak experiences. The Dream phase is a time for students to imagine what might be for their future through a process of self-reflection. For some students their future may be focused on completing the class, completing their degree program, or entering a new career field.

The second week involved another conversation and the use of the third factor in the 4D process, which is the Design phase. Participants discussed resources and strategies that would help students meet their developmental needs, which included working on the creation of their desired future. This was also a time of showing belief in the students and their abilities, while helping them reach for what they wanted to accomplish. During the third week that participants worked with students there were no scheduled contacts - the third week was planned as a time to allow students to work with the recommended resources and strategies provided during week two. The fourth and final week that participants worked with the selected students was characterized by the last factor in the 4D cycle, which is the Destiny phase. This conversation provided a sense of support for the students' progression towards working on their desired future, while utilizing the resources and strategies suggested by their instructors.

\section{Data Collection Instruments}

This researcher asked participants to become familiar with appreciative andragogy, which is based upon the organizational theory of appreciative inquiry, and how this concept could be applied as an instructional strategy within his or her online classroom. The participants were asked to select a predetermined number of learners within his or her online class, to evaluate his or her performance, engagement, and motivation in the class before and after the use of appreciative andragogy. To accomplish this task there were interviews conducted between the researcher and participants, worksheets were provided by the researcher and collected from the participants, journal entries were written by the participants and collected by the researcher, and other documents were collected from the participants that provided examples of instructional strategies utilizing appreciative andragogy.

\section{Data Collection}

There were a total of nine participants for this study, with eight facilitating online classes in a part-time capacity and one facilitating online classes in a full-time position. Three of the participants held a doctorate degree and previously participated in a research study. Six of the participants held a master's degree and had not yet participated in a research study. Participants' previous teaching experiences ranged from one to forty years, while participants' previous experiences teaching online ranged from eight months to nine years. Four of the participants recognized the concept of appreciative inquiry or were somewhat familiar with the term, one participant knew about appreciative inquiry as they utilize a constructivist approach to teaching, and four participants were not familiar with the term.

For most participants, they planned to add appreciative andragogy as an instructional strategy and begin implementation with a one-on-one phone conversation. One participant did not require any changes to their instructional strategies as they already use a constructivist approach to teaching. P1, P2, and P5 attempted phone contact with all of the selected students during the first week of the implementation phase. P3 began implementation after the initial bio assignment was completed by his/her students and P3 added questions to this assignment about goals and dreams. P4 approached students during the first week of implementation and discussed areas of needed improvement. P6 first asked students to self-reflect and consider their dreams. P7 asked students about their goals and dreams. P8 waited to contact students until they posted their introductions and completed the first assignment. P9 contacted students and asked them to talk about their progress, goals, and dreams. Most of the participants selected five students to work 
with during the implementation phase of the study. P3 selected a total of six students and P2 withdrew from the study prior to implementation. Most of the participants still had five students at the end of the implementation phase. P1 had a total of two, P3 had six, and P8 had four. There were a total of

thirty-seven students that went through the complete four-week implementation phase.

There were three forms of data collected for this research study and included interviews, worksheets that were completed by the participants, and journal entries submitted by the participants. The first participant (P1) served as a test case and a determination was made that there was no need to alter the study design, as the interviews were conducted as planned and the participant followed the implementation phase as designed. The participant interviews were all recorded and utilized semistructured, open-ended questions that allowed each participant to share their thoughts, ideas, knowledge, and experiences. The interviews were scheduled around the participants' availability, which included day and evening appointments. Each interview took an average of ten to thirty minutes to complete. The interviews provided the researcher with an opportunity to explain the underlying theories of appreciative andragogy and appreciative inquiry, to obtain feedback from the participants about their participation and answer any questions or concerns, and it allowed the researcher to hear about each participant's experience after working with appreciative andragogy during the implementation phase. Most of the participants provided meaningful responses and were willing to take the time to participate in each of the interviews. In addition, most of the participants were highly engaged in the study, they were interested in learning about appreciative andragogy and how to apply it to their online classroom, and they were willing to contribute their time, energy, and effort to the research study. The researcher took notes during the interviews and after the interviews were conducted the researcher transcribed each of the statements.

The participants were given worksheets that asked them to evaluate their present instructional strategies, the use of appreciative andragogy as an instructional strategy, along with the level of motivation, engagement, and performance for their selected students prior to and after the implementation phase. Most of the participants provided detailed responses and completed the worksheets within the one week period requested. The participants were also asked to record journal entries during the implementation phase to document their thoughts, feelings, and experience with the use of appreciative andragogy. Some of the participants completed the journal entries in detail and submitted them with the post-implementation worksheet. The journal entries gave a feel for the lived experience of the participants and documented the amount of time and thought that was put into the implementation phase. The journal entries also documented the challenges that were encountered during the implementation phase and the positive feedback received from the students. For those participants who did not submit journal entries, or journal entries with few details, their experience with the implementation phase was discussed during the final telephone conversation.

A concern for the data collection process was monitoring the students' progress as each participant worked with them and utilized the 4D cycle. During the implementation of appreciative andragogy, the destiny phase was the most difficult to assess since many of the students' dreams and goals went beyond the four-week timeline. Some of the students expressed their goals in terms of completing the class, their degree program, or obtaining a specific career. The participants could only monitor the students' progress at this point and continue to show belief in the students and offer resources. Another concern for the data collection process involved knowing the participants' progress and determining if they were following the research design during the implementation phase. A weekly follow-up email was sent to each participant during the implementation period and an outline of the implementation plan was included with each email to serve as a reminder. Some of the participants responded and provided a progress update. Overall, the participants followed the research design, participated in the phone conversations as requested, and conducted the implementation phase as planned. 


\section{Data Analysis}

After the data was collected, individual case reports were written to document the overall findings for each participant. Once the individual case reports were written, a cross-case summary report was completed to summarize common themes that emerged from the data. When sorting through the data, the researcher had to make a determination of the key points, the most important and relevant information, and the least important or least relevant information. The challenge was to accurately portray each participant and their unique viewpoint and experience working with appreciative andragogy.

\section{Research Question: How does the application of elements of appreciative andragogy as an instructional strategy for instructors positively affect online post-secondary classes?}

The participants indicated that appreciative andragogy was easy to implement, the methodology was effective, and the concept could be used by other online instructors. Appreciative andragogy positively affected online classes in three key ways and included the relationship between the instructor and their students, the ability of appreciative andragogy to change students' views of online classes, and the life-giving elements that appreciative andragogy influenced. Through the use of appreciative andragogy the instructor developed stronger working relationships with their students. The instructor was provided with an opportunity to get to know their students better by relating to them through their dreams and goals. The students found it meaningful that an instructor would invest additional time and show a concern for the student's success. The instructors felt connected with their students, they were able to develop a stronger rapport with their students, and the use of appreciative andragogy helped the instructor to be seen as a real person. The instructor's role was expanded to include acting as a mentor and by learning more about their students' needs they could tailor the class materials to meet those needs. The use of appreciative andragogy positively affected online classes by raising an awareness of the life-giving forces within the classroom and supporting those positive elements. The participants indicated that what gives life to the online classroom includes the students' motivation to learn, the class discussions, the interactions between the instructor and their students, and the students' life experiences.

\section{Research Question: How do online instructors apply elements of appreciative andragogy as a positive instructional strategy for online post-secondary classes?}

Appreciative andragogy was implemented through the use of a 4D cycle over a four-week time period. The first week was the discovery phase and involved contacting students to discuss their hopes, dreams, and peak experiences. The first week also included the dream phase or a time of reflecting on what is important and imagining what might be in the future. The process of discovery included appreciating the student's present qualities and abilities, along with the development of a mutual understanding between the instructor and the student. The dream phase also involved a time of selfreflection for the student and thinking about possibilities, which may involve completing their degree, gaining specific knowledge, or passing the class. The second week of the implementation phase involved contact with the students again to talk about resources and strategies that might help them meet their dreams and goals, which is the design phase of the $4 \mathrm{D}$ cycle. This phase was designed as a time for the instructor to show belief in their students, along with their abilities and the potential that each one holds. The third week of the implementation phase required no contact with the students, which provided time for the students to work with the resources and strategies suggested. The fourth week of the implementation phase was the destiny phase and included a follow up conversation with the students to find out if the students had attempted to utilize the resources and strategies provided. The destiny phase involves a time of creating what will be and often the students' dreams and goals would not be completed by the end of the course; therefore, the participants utilized this as a time of checking in with the student and offering their support and additional guidance.

\section{Research Question: How does the application of elements of appreciative andragogy as an instructional strategy for online instructors influence adult learner motivation?}

The participants indicated that peak motivation is evident when students are enthusiastic and 
engaged in the class, when their written responses exceed the assignment criteria, and they are at an above average performance level. Peak motivation is also observed when students are offering encouragement, assisting others, and they are sharing real-world examples and alternative perspectives. Students are at peak motivation when they are actively participating in the class discussions, showing an interest in the course, maintaining frequent communication with their instructor, applying what they have learned to their lives, and completing their assignments ahead of time. The use of appreciative andragogy influenced student motivation through the use of positive encouragement from their instructor. Some instructors used visualization to increase motivation, asking students to visualize successfully meeting their goals and dreams. Some participants noted that motivation was highest at the start of the class and appreciative andragogy helped to sustain that level of motivation throughout the class. Some participants found that students' motivation increased because of the strong working relationships that were developed during the implementation phase. The personal contact that the participants had with their students helped to develop a connection and the participants took a positive approach to working with their students. For this study there were a total of 37 students who experienced the use of appreciative andragogy. The participants noted that 16 students' levels of motivation remained unchanged, 19 students experienced a positive increase in their motivation, and two students demonstrated an overall decline in their level of motivation.

\section{Research Question: How does the application of elements of appreciative andragogy as an instructional strategy for online instructors influence adult learner engagement?}

The participants indicated that peak engagement can be observed through class discussions, along with students' interactions, their classroom presence, and the work they have submitted. Peak engagement occurs when students are actively participating in the class discussions and have a high level of interactions. Peak engagement also includes students who are sharing their knowledge and experiences, encouraging others, and engaging others in the discussions. During the implementation phase, some of the participants were discussing methods for increasing participation with their students, they were providing emotional support, and modeling active engagement in the class. Many of the participants found that increased engagement was often due to increased performance and motivation, which is an automatic process when those elements are emphasized. For this study there were a total of 37 students who experienced the use of appreciative andragogy. The participants noted that 10 students' levels of engagement in the class remained unchanged, 25 students experienced a positive increase in their engagement, and two students demonstrated an overall decline in their level of engagement.

\section{Research Question: How does the application of elements of appreciative andragogy as an instructional strategy for online instructors influence adult learner performance?}

The participants found that peak performance was demonstrated with the students' discussions and assignments. Peak performance included quality discussion responses, along with assignments that exceeded the objectives and criteria. Peak performance was also evident when students were submitting their assignments on time, demonstrating the use of critical thinking, challenging themselves to do better, maintaining frequent communication with their instructor, and earning an " $\mathrm{A}$ " overall for the class. During the implementation phase some of the participants were assisting their students with questions about the assignments, offering feedback about their performance, recognizing the students' contributions, challenging students to do more, discussing resources that are available to meet their developmental needs, and offering strategies for completing their goals. The participants noted that the students' performance increase because of these strategies used, along with the personal connection made. For this study there were a total of 37 students who experienced the use of appreciative andragogy. The participants noted that eight students' performance level remained unchanged, 27 students had a positive increase in their performance level, and two students demonstrated an overall decline in their level of performance. 
The Transformation of Online Teaching

\section{Results}

The data collected for this study led to conclusions about the potential of appreciative andragogy to influence adult learner motivation, engagement, and performance. These conclusions are drawn from an exploratory case study involving the implementation of appreciative andragogy within a live classroom; with the participants' lived experience providing the data.

\section{Research Question 1: "How does the application of elements of appreciate andragogy as an instructional strategy for instructors positively affect online post-secondary classes?”}

What was learned from this study is that the use of appreciative andragogy had a positive effect on many aspects of online post-secondary classes. When implemented as an instructional strategy a conscious shift in thinking occurred for the instructor and the students. For the participants, they began to discover the students' interests, abilities, goals, and potential through the use of one-on-one interactions, developing an individualized perspective and view of each student. From the students' perspective, they were encouraged to utilize critical thinking and self-reflection during their conversations with the instructor, causing a shift in their thinking and perceptions, which is believed to have led to cognitive and intellectual development. Through the use of appreciative andragogy the students felt a sense of value and inclusion in both the class and the learning process, which in turn had a positive impact on their motivation, engagement, and overall performance. This outcome matches the same results experienced within organizations when appreciative inquiry was utilized. Organizational employees experienced a sense of being valued because of the nature of the appreciative efforts utilized (Watkins \& Mohr, 2001).

\section{Research Question 2: "How do online instructors apply elements of appreciative andragogy as a positive instructional strategy for online post- secondary classes?”}

What was learned from this study is that appreciative andragogy could be applied as an instructional strategy for online instructors regardless of the subject matter. Participants were encouraged to take a caring approach to facilitation rather than forcing students to comply with the learning process. The participants sought the students' involvement and they adapted the process when students were unable to schedule all of the one-on-one conversations or were not interested in having more than one discussion. An important factor for successful learning within an online classroom environment is the ability of an instructor to provide continuous assistance (Reisetter \& Boris, 2004). The participants reached out to the students and expressed an interest in discussing their progress. For many of the participants this caring approach was already being utilized within their instructional strategies and most participants were already working to influence, develop, and improve their students' motivation, engagement, and performance. For these participants the use of appreciative andragogy did not feel like a completely new process rather it was a new developmental tool. It is unknown how effective appreciative andragogy would be implemented if the instructor's disposition was not similar in nature to the participants for this study. Most of the participants were already used to providing meaningful feedback and encouragement to support the development of their students, and they were readily available to provide assistance.

\section{Research Question 3: "How does the application of elements of appreciative andragogy as an instructional strategy for online instructors influence adult learner motivation?”}

During the implementation phase of appreciative andragogy the participants used visualization, questions, critical reflection, critical thinking, and direct contact as methods of having a positive impact on their students' level of motivation. These techniques were an addition to the positive methods already used by the participants to influence student motivation. The participants measured the motivation level 
of their students by such factors as the students' grades, performance, work product, and involvement in the class discussions. The participants made a determination of motivation levels based upon what they could physically observe or measure within their online class. What was learned in this study is that the development of a strong connection between the students and their instructor, along with a satisfactory class experience, often resulted in a positive sense of identity and sense of self-worth. In addition, strong working relationships that were developed throughout the implementation phase also led to students having the potential for a greater success in the learning process. Students often expressed the belief that they were valued by their instructor, which had a positive impact on their overall sense of self-worth throughout the class. Through the implementation of appreciative andragogy the participants indicated they were able to shift the students' thinking away from grades as a primary focus, to thinking about the meaning of those grades and the class towards meeting their long-term goals. While it was believed that this shift in thinking would cause a positive effect on student motivation, and the participants noted a positive reaction from students to the use of appreciative andragogy, the motivation levels reported were not always improved.

\section{Research Question 4: "How does the application of elements of appreciative andragogy as an instructional strategy for online instructors influence adult learner engagement?”}

What was learned in this study is that a strong working relationship between the instructor and their students is likely to increase students' levels of engagement in the class. The students were directly interacting with their instructor on a frequent basis and the instructor attempted to establish a positive and supportive tone with all of their communication. The use of an approach that is focused on students' needs, dreams, goals, and overall development is more likely to create a positive emotional reaction than an approach that is focused solely on students' weaknesses. This is the same lesson learned within organizations when change initiatives were changed from a deficit-based approach to one that considers strengths and contributions that employees are capable of making to the organization (Cooperrider, Whitney, \& Stavros, 2008). While there is a need for behavioral conversations at times, the use of appreciative andragogy provides an ability to build positive working relationships that allow issues and concerns to be openly discussed before behavioral issues develop. During the implementation phase it was also learned that students' active engagement led to increased participation in class discussions, which is the gauge participants often use to measure levels of engagement. Participants became consciously aware of the increased participation and believed that these students were fully engaged in the class because they were visible in the discussion boards. Many of the participants also found that engagement increased when motivation and performance were discussed through the one-on-one discussions-participants were providing strategies and resources that students could use to meet their developmental needs. As students felt supported by their instructor, and used all of the suggestions provided by the instructor, their level of motivation increased, their performance was notably improved, and their engagement in the class was visibly increased.

\section{Research Question 5: "How does the application of elements of appreciative andragogy as an instructional strategy for online instructors influence adult learner performance?"}

What was learned in this study is that the quality of student work products improved because of a strong connection between the students and their instructors. The one-on-one conversations provided detailed feedback that let the students know how they could improve their performance and what resources would help their progress. During the implementation phase the participants worked with a total of 37 students, and there were only eight students who did not have a change in their performance level over the four-week implementation period. This was the smallest percentage of students who did not experience a change when compared to the number of students who did not have a change in their 
The Transformation of Online Teaching

motivation or engagement levels. There were a total of 21 students who had a one level change in their performance, which was the highest percentage increase for a one level change, when compared to the students' level of change in their motivation and engagement. There were five students who experienced a two level change in their performance level and one student that experienced a three level change in their performance level. This indicates that for this study, appreciative andragogy had the greatest impact on students' overall performance. There were two students who experienced a decline in their performance level, which are the same two students who also experienced a decline in their level of motivation and engagement.

\section{Limitations}

This case study considered only the perspective of the online instructor as the instructor was responsible for implementing appreciative andragogy as an instructional strategy. The instructor either utilized appreciative andragogy effectively or determined that it was an ineffective instructional method. In addition, if the instructor already utilized qualities of appreciative andragogy in his or her instructional practice, the results reported would find little change in the student's performance, motivation, and engagement.

This case study is also limited in its focus on random applications of appreciative andragogy to online classes, rather than a procedure that has been established by an academic institution and supported through training and development efforts. The use of appreciative andragogy also depended upon the instructor's understanding of adult education, his or her willingness to implement all of the suggested uses as an instructional method, and his or her ability to gauge the effectiveness of this approach. This study would also be limited if the theory of appreciative inquiry, adapted as appreciative andragogy, could not be applied to an online classroom. Finally, this study was limited by the lack of scholarly research concerning the application of appreciative inquiry to an online classroom environment.

\section{Conclusions}

The use of appreciative andragogy was tested within eight online classes with a total of 37 students. While this is a small sample, the study did reach conclusions as a result of the implementation phase when appreciative andragogy was used as an instructional strategy during an ongoing class. The students' level of performance was measured before and after the implementation period when appreciative andragogy was utilized through a 4D cycle. After the implementation period, $73 \%$ of the students experienced a positive change in their performance level and $27 \%$ of the students experienced no change in their performance level or had a decrease. For student motivation, after the implementation period $51 \%$ of the students experienced a positive changed in their motivation level and $49 \%$ of the students remained unchanged or experienced a decrease. For student engagement, after the implementation period $68 \%$ of the students experienced a positive change in their level of engagement and $32 \%$ of the students remained unchanged or experienced a decrease. There were a total of two students who experienced a decrease for all three factors measured and these students not only experienced a decline, they also withdrew from the class.

The impact of appreciative andragogy extended beyond the measurements provided after the implementation period as there were other positive benefits to the use of appreciative andragogy. The measured indicators (motivation, engagement, and performance) reflected changes that could be observed or documented after a four-week implementation period. Since the participants were conducting one-onone discussions they were able to learn about the students' background, capacity, and abilities, and they were able to have a positive influence on the students' beliefs, perceptions, and involvement in the process of learning. All of the participants indicated that they took a positive approach to teaching prior to the implementation of appreciative andragogy and that this provided them was another resource, a motivational tool, and a structure for working with the students. The students became aware of the extra attention and direction that was being provided and many noticed the support, care, and concern being 
offered by their instructor. The participants helped their students learn about working towards peak motivation, engagement, and performance by encouraging students to do their best and relate their efforts to their hopes, dreams, and goals. The result of this new frame of reference for some of the students was a positive change in their performance, motivation, and level of engagement. For students who did not experience a noticeable change during that time period, it is possible that more time was needed to manifest those results, especially for students with limited prior academic experience and skills.

The use of appreciative andragogy provided many benefits for the participants and the conclusions reached after the implementation period indicate the potential that it holds to be applied to other online classes. The use of appreciative andragogy as an instructional strategy was easy to implement, even with limited prior knowledge of appreciative inquiry, because of the conversations held with each of the participants about the underlying concepts and related theories. The participants found that appreciative andragogy provided an effective relationship-building tool and it helped them put the focus of their conversations on the students' developmental needs, which were then tied to the students' future goals. The use of appreciative andragogy also modeled active motivation, engagement, and performance on the part of the participants, which in turn demonstrated that the participants were responsive to their students and actively present in the class.

It was concluded from this study that appreciative andragogy could be transferrable to any online classroom environment regardless of the class size or subject matter. During the implementation period appreciative andragogy was effectively utilized in undergraduate and graduate level classes. The primary reason for the effective use of appreciative andragogy was that it provided a language for participants to find common ground with their students and build effective communication. With a method that promotes communication and one-on-one interactions between the instructors and their students, the "distance" element is being taken out of the phrase "distance learning." The preferred method of communication for the use of appreciative andragogy, especially during the initial implementation period, was contact by telephone. For those students that could not be reached by telephone or did not prefer that form of communication, appreciative andragogy was still effective when the participants maintained the same level of active involvement with the students by email. Another conclusion reached as a result of the study is that the use of appreciative andragogy does require an investment of time by the instructor for the preparation and implementation of this concept as an instructional strategy. For this study all of the participants were willing to invest the time required as they indicated a desire to learn and an interest in developing their facilitation skills. It was concluded that the participants' willingness to try a new instructional strategy, or add a new instructional strategy as another facilitation tool, was necessary for the effective implementation of appreciative andragogy, due to the level of time and the positive frame of reference required when working with the students. Instructors must be open to trying a new approach and the participants in this study were not only willing to test a new approach, they also believed that they could coach and mentor students, allowing students to become co-creators in the learning process.

\section{Recommendations}

It is recommended that future studies of appreciative andragogy consider the need for clear definitions and standardized measurements of motivation, engagement, and performance factors as these qualities often overlap and influence one another. It should also be considered what type of training is necessary for instructors, before they begin implementing appreciative andragogy. Within this study participants were provided with a background and history of appreciative inquiry and were given an opportunity to ask questions and express concerns. There is a possibility that appreciative andragogy may be more effective if implemented at the college or university level, to establish standardized faculty training and encourage faculty to utilize the process.

Furthermore, the length of the implementation period should be another consideration as four weeks may not be long enough to accurately determine if there were behavioral changes or changes in motivation, engagement, and performance. It is possible that a longer time period may provide a better opportunity to accurately assess the overall impact and effect of appreciative andragogy. It is unknown if 
a larger class size, or implementing appreciative andragogy on a class-wide basis instead of a few selected students, would have any bearing on the outcome. On a class-wide basis there is going to be a much greater demand placed upon the instructor as the use of appreciative andragogy involves one-on-one interactions.

Future research concerning the use of appreciative andragogy may also consider the characteristics of an online instructor and the relationship of these personal characteristics to the effectiveness of appreciative andragogy. It is not known if all instructors will care about the developmental needs of their students, from the perspective of helping students reach peak motivation, engagement, and performance. In addition, it is unknown if most online instructors would be willing to adopt a new method of facilitation and adapt their current facilitation strategies. It should be considered whether or not the instructor's attitude about the process of learning and the students' involvement in that process has any effect on the implementation of appreciative andragogy. While appreciative andragogy takes a very positive approach towards student development, it is unknown if most online instructors would agree with that method and find the process easy to follow, implement, and utilize for all students.

\section{References}

Artino Jr., A. (2008). Promoting academic motivation and self-regulation: Practical guidelines for online instructors. TechTrends: Linking Research \& Practice to Improve Learning, 52(3), 37-45.

Bolton, F. C. (2006). Rubrics and adult learners: Andragogy and assessment. Assessment Update, 18(3), 5-6.

Bushe, G. R., \& Kassam, A.F. (2005). When is appreciative inquiry transformational? A meta-case analysis. The Journal of Applied Behavioral Science, 41(2), 161-181.

Caffarella, R. S. (2002). Planning programs for adult learners: A practical guide for educators, trainers, and staff developers (2nd ed.). San Francisco: Jossey-Bass.

Cooperrider, D. L., Whitney, D., \& Stavros, J. M. (2008). Appreciative inquiry handbook: For leaders of change (2nd ed.). San Francisco: Berrett-Koehler.

Creswell, J. (2003). Research design: Qualitative, quantitative, and mixed method approaches (2nd ed.). Thousand Oaks: Sage.

Dabbagh, N. (2004). Distance Learning. Quarterly Review of Distance Education, 5(1), 37-49.

Darabi, A. A., Nelson, D. W., \& Paas, F. (2007). Learner involvement in instruction on a complex cognitive task: Application of a composite measure of performance and mental effort. Journal of Research on Technology in Education, 40(1), 39-48.

Dirkx, J. M. (2006). Engaging emotions in adult learning: A Jungian perspective on emotion and transformative learning. New Directions for Adult \& Continuing Education (109), 15-26. 
The Transformation of Online Teaching

Forrest III, S. P., \& Peterson, T. (2006). It's called andragogy. Academy of Management Learning \& Education, 5(1), 113-122.

Goleman, D. (2006). Social intelligence: The new science of human relationships. New York: Bantam Books.

Keller, J. (2008). First principles of motivation to learn and e3-learning. Distance Education, 29(2), 175185.

Kelly, W. E. (2007). The structure of adult students' worries. Educational Research Quarterly, 31(1), 1726.

Kiely, R., Sandmann, L. R., \& Truluck, J. (2004). Adult learning theory and the pursuit of adult degrees. New Directions for Adult \& Continuing Education (103), 17-30.

Klecker, B. M. (2007). The impact of formative feedback on student learning in an online classroom. Journal of Instructional Psychology, 34(3), 161-165.

Knowles, M. S., Holton III, E. F., \& Swanson, R. A. (1998). The adult learner: The definitive classic in adult education and human resource development (5th ed.). Woburn: Butterworth-Heinemann.

Lyons, R., Kysilka, M., \& Pawlas, G., (1999). The adjunct professor's guide to success: Surviving and thriving in the college classroom. Boston: Allyn and Bacon.

Menchaca, M., \& Bekele, T. (2008). Learner and instructor identified success factors in distance education. Distance Education, 29(3), 231-252.

Merriam, S. (2001). The new update on adult learning theory. New Directions for Adult \& Continuing Education, (89), 3-13.

Merriam, S. (2008). Adult learning theory for the twenty-first century. New Directions for Adult \& Continuing Education: The third update on adult learning theory, (119), 93-98.

Miflin, B. (2004). Adult learning, self-directed learning and problem-based learning: Deconstructing the connections. Teaching in Higher Education, 9(1), 43-53.

Motteram, G., \& Forrester, G. (2005). Becoming an online distance learner: What can be learned from students' experiences of induction to distance programs? Distance Education, 26(3), 281-298.

Notar, C., Wilson, J., \& Montgomery, M. (2005). A distance learning model for teaching higher order thinking. College Student Journal, 39(1), 17-25.

Offir, B., Bezalel, R., \& Barth, I. (2007). Introverts, extroverts, and achievement in a distance learning environment. American Journal of Distance Education, 21(1), 3-19.

Orem, S. L., Binkert, J., \& Clancy, A. L. (2007). Appreciative coaching: A positive process for change. San Francisco: Jossey-Bass.

Osika, E., \& Sharp, D. (2002). Minimum technical competencies for distance learning students. Journal of Research on Technology in Education, 34(3), 318.

Ozuah, P. O. (2005). First, there was pedagogy and then came andragogy. Einstein Journal of Biology \& Medicine, 21(2), 83-87.

Palloff, R. M., \& Pratt, K. (2003). The virtual student: A profile and guide to working with online learners. San Francisco: Jossey-Bass.

Patterson, C., \& Crooks, D. (2002). A new perspective on competencies for self-directed learning. Journal of Nursing Education, 41(1), 25-31. 
Rachal, J. (2002). Andragogy's detectives: A critique of the present and a proposal for the future. Adult Education Quarterly, 52(3), 210.

Raelin, J. A. (2007). The return of practice to higher education: Resolution of a paradox. JGE: The Journal of General Education, 56(1), 57-77.

Robinson, C., \& Hullinger, H. (2008). New benchmarks in higher education: Student engagement in online learning. Journal of Education for Business, 84(2), 101-109.

Rovai, A.P., Ponton, M. K., Wighting, M. J., \& Baker, J. D. (2007). A comparative analysis of student motivation in traditional classroom and e-learning courses. International Journal on ELearning, 6(3), 413-432.

Sheridan, J. (2007). Lifelong learning in a postmodern age: Looking back to the future through the lens of adult Education. LLI Review, 2, 4-16.

Shieh, R., Gummer, E., \& Niess, M. (2008). The quality of a web-based course: Perspectives of the instructor and the students. TechTrends: Linking Research \& Practice to Improve Learning, 52(6), 61-68

Sogunro, O. (2002). Selecting a quantitative or qualitative research methodology: An experience. Educational Research Quarterly, 26(1), 3.

Van der Haar, D., \& Hosking, D.M. (2004). Evaluating appreciative inquiry: A relational constructionist perspective. Human Relations, 57(8), 1017-1036.

Van Oosten, E. B. (2006). Intentional change theory at the organizational level: a case study. The Journal of Management Development, 25(7), 707-717.

Walker, K., \& Carr-Stewart, S. (2004). Learning leadership through appreciative inquiry. International Studies in Educational Administration, 32(1), 72-85.

Watkins, J., \& Mohr, B. J. (2001). Appreciative inquiry: Change at the speed of imagination. San Francisco: Jossey-Bass / Pfeiffer.

Wefald, A., \& Downey, R. (2009). Construct dimensionality of engagement and its relation with satisfaction. Journal of Psychology, 143(1), 91-112.

Whitney, D., \& Trosten-Bloom, A. (2003). The Power of appreciative inquiry: A practical guide to positive change. San Francisco: Berrett-Keohler.

Wlodkowski, R. J. (1999). Enhancing adult motivation to learn: A comprehensive guide for teaching all adults (2nd ed.). San Francisco: Jossey-Bass.

Yballe, L., \& O'Connor, D. (2000). Appreciative pedagogy: Constructing positive models for learning. Journal of Management Education, 24(4), 474-483.

Zembylas, M. (2008). Adult learners' emotions in online learning. Distance Education, 29(1), 71-87.

Zepke, N. (2005). Diversity, Adult education and the future: A tentative exploration. International Journal of Lifelong Education, 24(2), 165-178. 